This article was downloaded by: [INCEIF]

On: 18 June 2012, At: 23:58

Publisher: Routledge

Informa Ltd Registered in England and Wales Registered Number: 1072954 Registered office: Mortimer House, 37-41 Mortimer Street, London W1T 3J H, UK

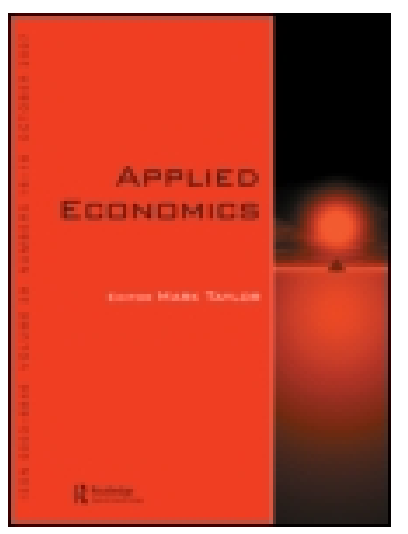

\title{
Applied Economics
}

Publication details, including instructions for authors and subscription information:

http:// www. tandfonline.com/loi/ raec20

\section{Foreign exchange exposure and impact of policy switch - the case of Malaysian listed firms}

\author{
Obiyathulla Ismath Bacha ${ }^{a}$, Azhar Mohamad ${ }^{b}$, Sharifah Raihan Syed Mohd Zain ${ }^{b} \&$ Mohd \\ Eskandar Shah Mohd Rasid ${ }^{\text {b }}$ \\ ${ }^{a}$ Department of Finance and Accounting, INCEIF, Lorong Universiti A, Kuala Lumpur, \\ Malaysia \\ ${ }^{\mathrm{b}}$ Department of Finance, KENMS, International Islamic University, Malaysia \\ Available online: 18 J un 2012
}

To cite this article: Obiyathulla Ismath Bacha, Azhar Mohamad, Sharifah Raihan Syed Mohd Zain \& Mohd Eskandar Shah Mohd Rasid (2013): Foreign exchange exposure and impact of policy switch - the case of Malaysian listed firms, Applied Economics, 45:20, 2974-2984

To link to this article: http:// dx. doi.org/ 10.1080/00036846.2012.684790

\section{PLEASE SCROLL DOWN FOR ARTICLE}

Full terms and conditions of use: http://www.tandfonline.com/page/terms-and-conditions

This article may be used for research, teaching, and private study purposes. Any substantial or systematic reproduction, redistribution, reselling, loan, sub-licensing, systematic supply, or distribution in any form to anyone is expressly forbidden.

The publisher does not give any warranty express or implied or make any representation that the contents will be complete or accurate or up to date. The accuracy of any instructions, formulae, and drug doses should be independently verified with primary sources. The publisher shall not be liable for any loss, actions, claims, proceedings, demand, or costs or damages whatsoever or howsoever caused arising directly or indirectly in connection with or arising out of the use of this material. 


\title{
Foreign exchange exposure and impact of policy switch - the case of Malaysian listed firms
}

\author{
Obiyathulla Ismath Bacha ${ }^{\mathrm{a}, *}$, Azhar Mohamad ${ }^{\mathrm{b}}$, \\ Sharifah Raihan Syed Mohd Zain ${ }^{\mathrm{b}}$ and \\ Mohd Eskandar Shah Mohd Rasid ${ }^{\mathrm{b}}$ \\ ${ }^{a}$ Department of Finance and Accounting, INCEIF, Lorong Universiti A, \\ Kuala Lumpur, Malaysia \\ ${ }^{\mathrm{b}}$ Department of Finance, KENMS, International Islamic University, Malaysia
}

This article undertakes an in-depth study of the foreign exchange exposure of Malaysian listed firms. We examine several issues related to firm-specific and overall exposure, including an evaluation of the efficacy of adopting a hard-peg on such exposure. Our sample consists of 158 listed firms and spans the 16 year period, 1990-2005. A multivariate model using four bilateral exchange rates is used to determine firm level exposure while panel data analysis using a random-effects Generalized Least Squares (GLS) model is used to determine system-wide or aggregate sample exposure. We find a total $71 \%$ of our sample firms to have significant exchange rate exposure, a rate substantially higher than that reported for most countries, especially developed ones. The US\$ is by far the single most important source of exposure with $63 \%$ of sample firms exposed to it. The sign of the beta coefficient for three of the four currencies are negative, implying that our sample firms are largely net importers in these currencies. We find exposure to be time variant and dependent on the sector within which a firm operates. Interestingly, the panel data analysis which measures aggregate exposure, shows the US\$ to be a significant source of exposure even with the adoption of the hard peg. The change in policy regime to a fixed peg following the crisis appears to have had no impact at either firm-level exposure or overall system-wide exposure.

Keywords: firm-specific; exchange rate; exposure; policy; switch

JEL Classification: E42; F31; F39

\section{Introduction}

The extent to which exchange rate exposure affects firm value remains an interesting empirical question. Previous studies that have examined this issue, in the context of the US and other developed markets, have found minimal impact of exchange rate exposure on firm value. This should not be surprising since the US and developed European markets are among the least open economies. Foreign trade as a ratio of Gross Domestic Product (GDP) is small for these countries. When the issue is examined for small and open emerging markets, the results have been vastly different. Exchange rate exposure appears to impact a much larger proportion of firms within emerging economies and at a much higher magnitude (Parsley and Popper, 2006). Yet, other studies have shown that the direction of impact, whether positive or negative depends on whether the firms are net importers/exporters and the sector of the economy that they operate within.

Exchange rate exposure can be broadly defined as the extent to which changes in exchange rates affect stock returns and thereby firm values. In their seminal paper, Adler and Dumas (1984), argue that a firm experiences exchange rate exposure if

*Corresponding author. E-mail: obiya@inceif.org; obiyathulla@yahoo.com 
its value is affected by changes in exchange rates. This definition provides researchers the convenience of measuring exposure as a coefficient in a linear regression of stock returns on changes in exchange rates. While the size and sign of these coefficients gives the magnitude and direction of the exposure, there are two variants of exposure transaction or operating. Transaction exposure results from the firm undertaking foreign currency denominated transactions, the home-currency value of which changes as exchange rate changes. Operating or economic exposure on the other hand results from the firm operating in a sector of the economy which is subject to foreign competition. The coefficient of the regression equation therefore captures the net impact on the firm of both the direct, transaction exposure and the indirect operating exposure.

In addition to the firm-specific factors, exogenous factors like the exchange rate regime in place, monetary policy thrust and the availability of instruments to manage the exposure, would also be determinants. Since these determinants are dynamic, it is possible that exchange rate exposure of firms may be time variant. And indeed several studies, notably Muller and Verschoor (2007) and Chue and Cook (2008) have documented it as such. Where a firm's profitability is concerned, it is obvious that exchange rate changes could affect it in multiple ways. Where the exposure is indirect or some combination of direct and indirect exposure, the net impact on a firm's profitability and value will be hard to tell. Framing the definition in line with Adler and Dumas (1984) enables us to side-step these inconvenience and explains the heavy use of this definition in the literature.

\section{Motivation/Justification for Study}

The objective of this study is to examine the extent of exchange rate exposure that Malaysian listed firms face and the impact on such exposure of changes in exchange rate policies. Our period of study is the 16 year period, January 1990-December 2005. There are several reasons why Malaysian companies would represent an interesting case for the study of exchange rate exposure. Malaysia is a classic case of a small openeconomy, heavily plugged into the world economy. A trade reliant nation, it typically has a Foreign Trade Ratio (FTR $)^{1}$ in excess of $200 \%$. Foreign trade is key to the economy and has always been so. Malaysia's geographical location midway between India and China and the so called 'trade winds' have enabled Malaysia to be a centre of entrepot trade since historical times. Thus, despite its size, Malaysia falls within the top 20 trading nations of the world. Though manufactured goods constitute the largest component of exports, commodities such as palm oil, rubber, tin, timber and oil and gas continue to be a sizeable portion of exports. While the majority of manufactured exports originate from foreign-owned Multinational Corporations (MNCs), often located within designated free-trade zones, commodity exporters tend to be locally-owned firms. Since most of these commodities have an international price, the commodity exporters are essentially price-takers. From an exposure viewpoint, the commodity exporters typically have revenues in US\$ since the international price is US dollar denominated. Their costs, on the other hand would mostly be in Malaysian Ringgit (MYR).

Aside from geographical and structural factors, policy wise, there are a number of reasons why Malaysia presents an interesting case. Though the country has traditionally had liberal policies with regards to capital flows and currency convertibility, Malaysia adopted stringent capital controls and a currency peg of the MYR to the US\$ following the East Asian currency crisis of $1998 .^{2}$ These were part of Malaysia's 'unorthodox' policy response to the perceived speculative attack on the currency. While the capital controls were for a period of 1 year, the currency peg remained until July 2005. From an empirical viewpoint, the impact of these varying policy regimes on currency exposure of firms ought to be useful.

Despite this very interesting blend of factors, with the exception of Parsley and Popper (2006) who include Malaysia as one of their 11 sample countries and Muller and Verschoor (2007) who include Malaysian firms as part of a study on Asian exposure, we are unaware of any in-depth study of the currency exposure of Malaysian listed firms. Our article benefits from the advantage of longer available data to fully cover the period of the currency peg. Unlike the earlier two studies, being Malaysia focused, this article is able to examine episodes/events not within the scope of the previous studies. We examine more companies, undertake sectoral analysis and cover a much broader scope of issues. This article contributes to existing literature in a number of ways. First, we focus on a small and very open economy, which few previous studies have done. Second, and more importantly, we examine the consequences of a drastic enforced change in exchange rate regime on the exposure of firms.

The article is divided into six sections. Section III below examines relevant previous literature and synthesizes the key findings. Section IV, presents our research questions and describes our data and methodology. In the subsequent Section V, we present our results and analysis. The final section concludes by drawing out key lessons and implications for policy.

\section{Literature Review}

The issue of exchange rate exposure on firm value appears to have been rekindled in recent years. Increased exchange rate volatility, currency crises and the renewed interest in regional exchange rate arrangements may be some of the reasons for this. Dominguez and Tesar (2006), examine the relationship between exchange movements and firm values for eight industrialized and emerging markets. They find that a significant proportion of their sample firms have the exposure. This exposure, however, depends on the specific exchange rate and varies over time. They attribute the time variance in firm level exposure to firms dynamically adjusting their behaviour in response to exchange rate risk. Ihrig and Prior (2005) examine whether the type of exchange rate used and the size of the

\footnotetext{
${ }^{1}$ Computed as [(Exports + Imports)/GDP], for 2007, the FTR was 200.2\% GDP.

${ }^{2}$ On 1 September 1998 Malaysia announced the imposition of a 1 year moratorium on capital outflows (excluding current account outflows) and the peg of the MYR to the US\$ at 3.80 MYR per US\$.
} 
movement matters in exchange rate exposure of the US manufacturing firms. Based on a sample of US multinational firms and domestic ones, they find that different industries may have exposures only to specific exchange rates. This implies that the use of a trade weighted index as earlier studies have done, may have underestimated the extent of exposure. They also show that some firms may have exposure only during crisis periods whereas others during normal fluctuations in exchange rates.

Two studies, Parsley and Popper (2006) and Muller and Verschoor (2007) focus on exposure among Asian firms. The first, examines firm level exposure across 11 Asia-Pacific countries. They conclude that Asia-Pacific firms are significantly exposed to exchange risk and have substantially higher exposure than firms of industrialized countries. The extent of exposure, though time varying has not diminished. In terms of currencies, they find movements in the US\$, the Yen and Euro to be important sources of exposure in a few countries. Of particular interest to this study, they find that 'exchange rate pegs appear to do little to alleviate the widespread exposure against currencies other than the peg'. Asian countries have had a range of soft and hard-pegs. In their sample, only two countries had hard pegs: Hong Kong and Malaysia. While Hong Kong's peg to the US\$ is maintained throughout their study period, their study which ends in December 2002 only covers approximately the first half of the nearly 7 years over which the Malaysian Ringgit was pegged to the US\$. Thus, where Malaysia is concerned, their conclusion would certainly need further validation. ${ }^{3}$

Muller and Verschoor (2007) confirm the significant exchange rate exposure of Asian firms, mostly, to the US\$ and the Japanese Yen. 70\% of sample firms had long term exposure to the US\$. A depreciating Asian (home) currency has a net negative impact on stock returns. Implying that, most of their sample firms are net importers. They also show that the extent of exposure often depends on the return horizon chosen. Short horizons such as weekly returns may underestimate exposure whereas long ones such as 3 month return horizons, may overestimate them.

In a single country study, De Jong et al. (2006), examine firm-specific exposure of Dutch firms. Over their 5 year study period, they find that over $50 \%$ of their sample firms are significantly exposed to exchange-rate risks. Contrary to Muller and Verschoor (2007), they report that a depreciation of the Dutch guilder benefits their sample firms. Thus, these firms must be the net exporters. They also show that the use of a trade-weighted currency index and the use of individual exchange rates are complements. Rees and Unni (2005), who examine firm level exposure among French, German and the UK firms, report findings similar to De Jong et al. (2006), home currency depreciation, especially against the US\$ benefits the sample firms. Clearly, the direction of trade and whether one is a net importer or exporter can explain whether the impact of the exposure would be positive or negative. However, as Chue and Cook (2008) find from studying 15 emerging markets over 6 years, the negative impact of home currency depreciation which is significant in one sub-period, disappears in a later period.

Examining Turkish firms over a 7-year period, Kiymaz (2003) reports that the degree of exposure varies by the sector in which the firm operates. Certain sectors are subject to much higher level of exposure, usually due to higher reliance on foreign trade and/or greater presence of foreign competition. Interestingly, he also finds that the exposure of all sectors industries was lower in the period following the Turkish Lira Crisis. The lower exposure post-crisis is attributed to the increased attention of firms to their currency exposure.

A number of other papers have reported results that may be peripherally related to this research. Aquino (2006) examines, Filipino stock returns pre/post-Asian currency crisis. Though stock returns were unaffected by exchange rate volatility in the pre-crisis period, post-crisis he finds a risk premium for stocks with currency exposure. Wong and Tang (2009) show variability in the real exchange rate to have positive influence on Malaysian semi-conductor exporters and by implication on their stock returns. Phylaktis and Ravazzolo (2005), examine the short- and long-run dynamics between exchange rates and stock prices for a group of Pacific Basin Markets. ${ }^{4}$ Their findings suggest that stock and exchange rate markets are positively related and that the US stock market acts as a conduit for this links. Interestingly, they find that 'foreign exchange restrictions are not an important determinant of the link between stock and foreign exchange markets on the one hand and between the domestic capital and world capital markets on the other hand'. Lee et al. (2011), find significant spill over from stock returns to exchange rates of six Asian countries. They show correlations between stock and currency markets to have increased in recent times.

Synthesizing the above papers with several others that have examined firm level exposure, a number of common themes are evident. First, firm-specific exposure varies by country, time and industry sector. Second, the chosen exchange rate matters. Using a trade weighted index tends to underestimate exposure. The return horizon chosen also matters. Short horizons such as daily and weekly returns underestimate exposure whereas long ones like quarterly returns may overestimate them. Third, firm level and overall market exposures are different. Fourth, firms dynamically adjust their behaviour in response to exchange rate risk. Finally, where emerging markets are concerned, share values of most firms are negatively affected by home currency depreciation.

\section{Data and Methodology}

Given the key findings from previous studies and our objective of evaluating the exchange rate exposure of Malaysian listed firms and the consequences of policy change, we formulate the following four research questions:

(a) What is the extent of currency exposure among Malaysian listed firms?

(b) How time variant is this exposure?

\footnotetext{
${ }^{3}$ In evaluating exposure over time, they have subdivided their sample period into three equal sub-periods of three (3) years each. Such subdivision, however, does not match the events/episodes that had an impact on exchange rates, especially in the case of Malaysia.

${ }^{4}$ Their data includes the Malaysian Stock Index. Their period of study is $1980-1998$.
} 
(c) What was the impact of the change in exchange rate regime on exposure of firms?

(d) How extensive is the variation in exposure by industry sectors?

In identifying the needed data, we began with a list of all firms that were continuously listed on Malaysia's stock exchange, Bursa Malaysia, from 1990 onwards. Eliminating for suspensions, trading halts, lack of trading volumes and other gaps in data, we are left with 158 companies. For these 158 firms, we computed monthly returns from January 1990 until December 2005, a period of 16 years. In examining firmspecific exposure, we follow Parsley and Popper (2006) and De Jong et al. (2006) of using several bilateral exchange rates. Aside from the US\$, which is an obvious candidate we looked at previous literature and Malaysia's direction of trade for relevant foreign currencies. Based on direction of trade, other than the US\$, Yen, Chinese Yuan, British Pound, Singapore \$ and the Euro would all be relevant.

Of these, the Euro and the Chinese Yuan had to be dropped. The Euro for its short tenure and the Chinese Yuan for the serious multicollinearity problem given its 'peg' to the US\$. Thus, we use the monthly bilateral exchange rates of the US\$, the Singapore dollar (SGD), Yen (JPY) and the Pound (GBP) against the Malaysian Ringgit (MYR). We define the exchange rate as the number of MYR per unit foreign currency. The data were sourced mainly from Bloomberg and Bursa Malaysia. In addressing our four research questions, we analyse both across firms (sectoral analysis) and over time (by different sub periods). Broadly speaking, we do two levels of analysis. We use firm-specific exposure for each of our sample firms and then an overall/aggregated analysis. The latter being the panel data analysis.

Following, De Jong et al. (2006) and Parsley and Popper (2006), we measure firm-specific exchange exposure as follows:

$$
R_{i t}=\alpha+\beta_{1} \mathrm{USD}+\beta_{2} \mathrm{SGD}+\beta_{3} \mathrm{JPY}+\beta_{4} \mathrm{GBP}+e_{t}
$$

$R_{i t}$ is the returns of stock $i$ in month $t$ less the returns on the market index for month $t$.

The market index is proxied by the 100 stock, KLSE CI.

The use of multiple bilateral exchange rates instead of a single trade weighted exchange rate has the advantage of allowing the data/model to select which exchange rate is significant for an individual firm. Equation 1 essentially states that a firm's excess return is a function of, or is determined by changes in the four exchange rates. By taking excess rather than total returns, we are measuring firm level marginal exposure. The implicit assumption of constant variance in Equation 1 is often untrue with time series financial data. To overcome this problem, in line with previous studies, we add a Generalized Autoregressive Conditional Heteroscedasticity (GARCH $(1,1))$ specification to Equation 1. In addition, De Jong et al. (2006), show that specification as in our Equation 1, tends to underestimate exposure because of multicollinearity in the exchange rates. They suggest using the Wald test to correct for this. Accordingly, to correct for potential multicollinearity we perform the Wald test to test whether all four exchange rate coefficients are simultaneously equal to zero. We do this for all firms that showed no exposure using Equation 1. Where the Wald test is rejected, we identify the currency coefficient that is significant and include that firm as being exposed to that currency.

In analysing exchange rate exposure on an overall basis, we do panel data analysis using a random-effects Generalized Least Squares (GLS) regression model. This is done by stacking each of our 158 sample firm's data, as panel data and estimating an overall Seemingly Unrelated Regression (SUR). The advantage of this is that, it accommodates the cross sectional correlation between the samples. While the model specified in Equation 1 would enable us to estimate exchange rate exposure for an individual sample firm, Equation 2, enables us to estimate overall exposure across all sample firms and subgroups of firms.

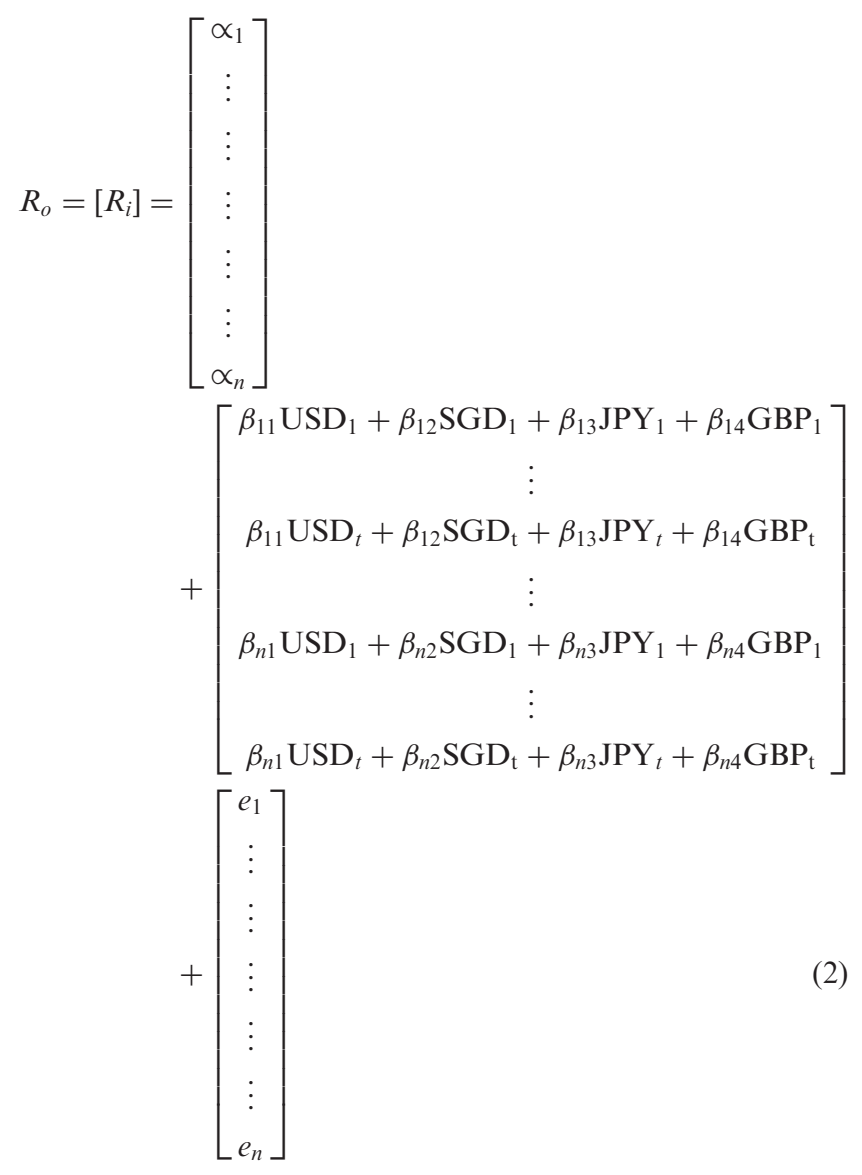

where, $R_{o}$ is the overall/across sample return.

\section{Results and Analysis}

\section{Firm-specific exposure}

Tables 1 and 2, show the incidence of exchange rate exposure among our sample of Malaysian listed firms. Regressing Equation 1 and testing at a 5\% level of significance, a total of $112 \%$ or $71 \%$ of our 158 sample firms have significant exchange rate exposure. Though this is a very high level of exposure, it should not be surprising for the following two reasons. First, as pointed out earlier Malaysia is a very open economy with heavy dependence on international trade. Second, previous studies, notably Muller and Verschoor 
Table 1. Firm-specific exposure by number of currencies

\begin{tabular}{llc}
\hline Currencies exposed to & Number of firms & $\%$ to exposed firms \\
\hline Zero & 46 & 0 \\
One & 76 & 68 \\
Two & 29 & 26 \\
Three & 6 & 5.4 \\
Four & 1 & 0.8 \\
\hline
\end{tabular}

Notes: Total firms with exposure to at least one currency $=112$ $(112 / 158=71 \%$ of firms have exposure $)$.

Table 2. Incidence of exposure by currency

\begin{tabular}{lll}
\hline Currency & Number of firms & $\%$ of exposed \\
\hline USD & 70 & 62.5 \\
SGD & 32 & 29 \\
JPY & 22 & 12.5 \\
GBP & 32 & 29 \\
\hline
\end{tabular}

Note: ${ }^{\text {a }}$ The sum total is more than $100 \%$ since many firms have exposure to more than one currency.

(2007), have documented such high incidence among Asian firms. ${ }^{5}$ Only $46 \%$ or $29 \%$ of our sample firms have no exposure to any of the four currencies. The vast majority of the exposed firms, $68 \%$ are exposed to a single currency. A one third of the exposed firms have exposure to more than one currency. A single firm had exposure to all four currencies.

Table 2 shows the breakdown of exposure by currency. Not surprisingly, close to two-thirds $(62.5 \%)$ of all exposed firms have exposure to the US\$. The US\$ is by far the most important source of exposure for Malaysian firms. The Singapore dollar (SGD) and the sterling pound (GBP) both share second place with $32 \%$ of exposed firms. Though second, it is worth noting that it is a very distant second placing. Surprisingly, despite Japan's eminence as a major trading partner of Malaysia, only one in eight $(12.5 \%)$ of exposed firms have exposure to Yen.

To examine the direction and magnitude of the exposure we refer to Table A1 in the Appendix. Panel A of the table shows the results of firm-specific exposure using Equation 1, Panel B shows the overall exposure across all sample firms, determined using Equation 2. From Panel A the arithmetic mean coefficient is negative for three of the four currencies, implying the firms are net importers. Appreciation of the foreign currency causes a reduction in stock values/returns. The coefficient for the US\$ has the largest SD and range. Of the 70 firms with significant exposure to US\$, an equal number have positive as negative coefficients. Panel B is the more important part where direction and magnitude of exposure for overall market is concerned. The US\$, Yen and Pound have negative betas whereas the SGD positive. The implication is that our sample firms are net importers in the first three
Table 3. Firm-specific exposure by sub-periods

\begin{tabular}{llllll}
\hline & US\$ & SGD & JPY & GBP & Total \\
\hline Overall & 70 & 32 & 22 & 32 & 156 \\
Crisis & 30 & 11 & 30 & 12 & 83 \\
Peg & 33 & 32 & 20 & 11 & 96 \\
\hline
\end{tabular}

currencies but net exporters where the Singapore dollar is concerned. Aside from being consistent with findings of previous studies, this result is logical since a substantial portion of Malaysia's exports are through Singapore. In terms of statistical significance, only two currencies the US\$ and GBP would be significant at 5\%. The Singapore dollar (SGD) would be significant at $10 \%$. However, the yen is insignificant. Taken together, Table A1 shows the overall importance of the US\$. Not only does it affect the most of the firms, it also has the highest coefficient. A $1 \%$ appreciation of the US\$ against the Malaysian Ringgit would cause a $0.25 \%$ reduction in firm value. One can imagine the destruction in firm value when the US\$ rose sharply against the MYR during the currency crisis of 1997/1998. The surprise result is the strong influence of the GBP. Though it impacts a smaller number of firms, its beta is marginally higher than the US\$.

\section{Exposure over time and exchange rate regime}

In addressing our second question about whether exposure varies over time, we divide our 16 year study period into subperiods. From an exchange rate viewpoint, there were two key events that would have impacted exchange rate exposure. First, the East Asian currency crisis of 1997/1998 and second, the fixed peg regime that followed. Accordingly our subdivision is as follows: a first sub-period from June 1997 to August 1998 which covers the period of the crisis and a second subperiod, September 1998 to July 2005 which was the period over which the Ringgit was pegged to the US\$. ${ }^{6}$ With this subdivision, we would also be able to determine what the impact of the peg was on firm level exposure, our third research question. Table 3 shows the breakdown of exposure by currency for the two sub-periods and the overall period.

The difference in the number of firms exposed is striking. The number of firms with significant exposure shows a marked decline in the crisis and peg period relative to overall period. This is particularly true for the US\$ and GBP, both of which were highly significant in Table A1. The number of firms with exposure to the US\$ which was 70 for the overall period, falls to 30 in the crisis period and remains at 33 in the peg period. There appears to be a somewhat 'permanent' reduction in exposure where the US\$ is concerned. Though surprising, these results are in line with Kiymaz (2003) who reports a reduction in exposure for Turkish firms in the period following the Turkish Lira Crisis. Ihrig and Prior (2005) also report a similar reduction in exposure among multinationals following the Asian currency crisis.

\footnotetext{
${ }^{5}$ They show that more than $70 \%$ of their sample firms have exposure to the US\$.

${ }^{6}$ The Ringgit was pegged to the US\$ from 1 September 1998 to 21 July 2005, a period of about 7 years.
} 
The yen and SGD which were insignificant earlier, now show a slightly different picture. Aggregating across all firms and currencies, the incidence of firm-specific exposure falls to about $50 \%$ and $60 \%$ respectively, during crisis and peg period relative to that of overall period. ${ }^{7}$ Despite the sharp reduction in the number of firms that were exposed, the magnitude of exposure is a different story. Panel A of Table A2 shows the mean coefficient, max and min values and breakdown by sign of the coefficient for the overall period and the two subperiods. The mean coefficient is simply the arithmetic average of coefficients across all sample companies. Notice the very substantial increase in mean coefficient for all the four currencies during the crisis. For the US\$, SGD and JPY, the mean coefficient during the crisis period is more than 10 times higher than that of the overall period. Whereas only the GBP was statistically significant for the overall period at the $5 \%$ level, all four currencies are significant during the crisis. What this numbers tell us is that, firm-specific exposure was on average more than 10 times higher during the period of the currency crisis. In addition to the large increase in the magnitude of exposure, the range and $\mathrm{SD}$ is also much higher. Given the exchange rate volatility during the crisis, this is not surprising. When we look at the direction of the exposure as represented by the sign of the beta coefficient, we again see interesting differences. Whereas in the overall period, there was an equal number of firms with $(+)$ and $(-)$ signs for US\$ exposure, during the crisis, it is heavily skewed to negative coefficients. Of the 30 firms with significant exposure to US\$ in the crisis period, only two have $(+)$ coefficients, the remaining 28 have negative coefficients. This means that at the firm level, the vast majority of Malaysian firms were susceptible to an appreciation of the US\$ against the Ringgit and not the other way round, where appreciation of the Ringgit against the US\$ would have helped.

The last four columns of Panel A show firm-specific exposure during the period of the currency peg. The mean coefficients for all the four currencies are much lower than what they were in the prior crisis period. However, they are still higher than that of the overall period. Thus, though lower than during the crisis, firm-specific exposure was on average higher during the peg than that of the overall period. The US\$ and SGD are once again insignificant. That the US\$ is insignificant should not be surprising given that the Ringgit is now pegged to the US\$. The Yen and GBP remain as significant source of exposure. Interestingly, the beta coefficient of the Yen which was positive earlier is now negative. There also appears to be a better balance between the number of firms with significant positive and negative coefficients. Taken together, what this results tell us is that, during the 7-year peg period, firm-specific exposure resulted not from the US\$ but from the other currencies, the Yen and GBP in particular. The US\$ had an impact on firm values, but not significantly. Given the Malaysian government's stated rationale for the currency peg, these results are consistent.

Panel B of Table A2 shows the results of panel data analysis using Equation 2, for the two sub-periods. Again we see the much higher beta coefficients and therefore higher exposure for all the four currencies during the crisis. With the exception of SGD which comes close, the other three currencies are significant. These results are similar to the firm-specific numbers of Panel A for the crisis period. Comparing the peg period results using Equation 2 with the firm-specific results for the same period, we again see similarities. The size of the beta coefficients had reduced, as was the case earlier. The signs of the coefficient are also similar; the SGD is the only currency which is not negative. The one inconsistency is the US\$. The US\$ which was insignificant where firm-specific exposure was concerned, is now significant and strongly so. In fact all the four currencies, including the SGD are now significant. While the Ringgit was only pegged to the US\$, it would fluctuate against the other currencies as much as the US\$ does. Thus, continued exposure to the other currencies is not a surprise. That the US\$, despite the peg, remains a source of exposure to Malaysian firm values/stock returns is a puzzle. Even so, this is a result consistent with the findings of Dominguez and Tesar (2006) who show that firm-specific and overall exposures are different. Firm level exposure they argue, is time variant, changes signs, differs by sector and is otherwise dependent on firm level dynamics. Exposure at the aggregate economy level however, is shown to be fairly constant. It is precisely this aggregate level exposure that our Equation 2 is measuring. Our results reinforce Dominguez and Tesar's (2006) proposition that firm-specific and overall exposures are different.

\section{Is firm-specific exposure time variant?}

Going by what Table 3 showed, it is fairly evident that firmspecific exposure does vary with time. This appears to be the case for all the four currencies. To confirm, if indeed, exposure is time variant we re-examined the incidence of exposure for each of our sample firms over the three period categories. The objective is to see if a firm with exposure in one period also shows exposure in another. To avoid clutter, we focus only on exposure to the US\$. Figure A1 and the Venn diagram accompanying it show the results. Cumulating across all three period categories, there were a total of 94 individual firms with US\$ exposure. Of these, as seen in the Venn diagram, only two companies had consistent exposure to the US\$ over all the three periods. All other exposed companies, show no significant exposure in at least one of the other periods. Of the 70 firms that showed up as having significant US\$ exposure for the overall period, 36 did not have exposure either during the crisis or peg period. Eight firms had exposure only during crisis while 13 only during the peg period. Consistent with findings of earlier studies, we can only conclude that firm-specific exposure is dynamic with its incidence being time variant.

\section{Analysis by sector}

Several previous studies have noted the variance in currency exposure by sector of the economy. In line with this, we had formulated our last research question to examine the extent to which exposure varies between firms in different industry sectors. Our sample of 158 companies spans the 12 sectors which comprise all the listed firms on Bursa Malaysia. Though the distribution is uneven, 98 of our sample companies were within the four largest listed sectors i.e., (i) Trading and Services, (ii) Plantation, (iii) Industrial Products and (iv)

${ }^{7}(83 / 156$ for crisis period) and (96/156) for peg period $)$. 
Finance. Since the remaining samples were thinly spread out over the other eight sectors, we focus our sectoral analysis on only the above four sectors.

Table A3 shows our results. Panel A shows the number of firms with significant exposure by currency and sector. The large decline in the number of firms exposed during the crisis relative to overall period, seen earlier in Table 3 is evident again, especially in the case of the US\$. The higher incidence of exposure in the period of the peg relative to the crisis period appears to be even more prominent here.

Looking across Panel A of Table A3, notice that the number of firms with significant US\$ exposure is higher during the peg relative to crisis. Surprising, but consistent with that we saw in Table A2. One sector that stands out in contrast to the others is the plantation sector. This sector consists mostly of oil palm and/or rubber plantation operators. Of the four sectors, the plantation sector is the most involved in international trade with exports constituting a large portion of sales. Besides being net exporters, they are price-takers with their commodity products having an international price denominated in the US\$. Given these, we see some interesting dynamics for the plantation sector. Though eight plantation firms, $42 \%$ of the sector's sample, had significant exposure to US\$ in overall period, none were exposed during the crisis to the US\$. Thus, the crisis had minimal impact on the valuation of plantation firms. Yet, during the period of the peg to the US\$, the sector experiences higher exposure to the US\$ with five firms having significant exposure.

The mean coefficient for each sector by currency and subperiod is shown in Panel B of Table A3. Again the plantation sector stands out. Mean coefficient is a positive 1.27 for the overall period, reduces to zero during the crisis and increases to 3.1 during the US\$ peg. As seen from Panel A, exposure for the plantation sector increased during the peg, though in a favourable way. When we examined the signs of the coefficient for firms with significant exposure within the plantation sector, we found them all to have positive coefficients. All the eight plantation firms that had significant exposure in the overall period had positive beta coefficients just as all the five in the peg period had. This is one sector that is highly export-driven and appears to have benefitted from the switch in exchange rate regime. Comparing between sectors and over the different periods tells us two important things. First, there are obvious differences in the type and extent of exposures among the sectors. Second, for a given sector, the type or direction of exposure, whether positive or negative, varies over the different subperiods. Surmising from these results, one can only conclude that exchange rate exposure not only varies by sector but as we saw earlier is also time variant.

\section{Conclusion}

This article constitutes an in-depth study of the foreign exchange exposure of Malaysian listed firms. Being a country-specific study, it examines several issues related to exposure, including an evaluation of the efficacy of adopting a hard-peg on firm-level and system-wide exposure.

We find that a total $71 \%$ of our sample firms have significant exchange rate exposure. This extent of firm-specific exposure is higher than that reported for most countries, especially developed ones. The US\$ is by far the single most important source of exposure with $63 \%$ of sample firms exposed to it. The GBP and SGD are a distant second. Aggregating across all sample firms, the US\$ and GBP are significant sources of exposure whereas the two Asian currencies, the Yen and SGD are not. The sign of the beta coefficient for the US\$, GBP and Yen are negative, implying that our sample firms are largely net importers in these currencies. We find exposure to be time-variant and dependent on the sector within which a firm operates. Very few of our sample firms had consistent exposure over different sub-periods. Sectors like plantation which is heavily reliant on exports and has a US\$ denominated price for its products, show significantly positive beta coefficients to the US\$, had minimal impact during the crisis and benefitted from the peg.

While these results were by and large consistent with findings documented for other markets previously, where our results differ is in the substantial variance we find between firm-level and aggregate cross sample exposures. At the micro level, firm-specific exposure shows a marked reduction during the crisis period with only about half the number of firms showing significant exposure. This marked reduction remains in the post-crisis peg period, though there is a slight increase in the number of firms exposed. The US\$ ceases to be a significant source of exposure where firm-specific exposure is concerned. However, our panel data analysis which is designed to measure aggregate exposure, shows the US\$ to be a significant source of exposure even with the adoption of the hard peg. Collectively, what these results seem to be telling us is that the outbreak of the crisis forced firms to better manage their exposure, thereby resulting in fewer firms with significant exposure. However, the much touted change in policy regime to a fixed peg following the crisis appears to have had no impact at either firm-level exposure or overall system-wide exposure.

In a sense, these results validate the findings of Parsley and Popper (2006) who argue that though exchange rate regimes changed drastically in several of their sample countries, exchange rate exposure had not reduced. That, exposure arising from the fluctuation of the Ringgit to other currencies would continue following its peg to the US\$ is to be expected, but how do we reconcile the fact that the US\$ continues to be a significant source of exposure to Malaysian companies even during the peg?

To see how this is possible, we need to keep in mind two factors, first, our definition of exposure and second the nature of the peg. Recall that in the context of this study, we use the standard definition of exposure, as changes in the market value of a listed firm as a result of changes in exchange rates. This raises the question, how could the US\$ continue to impact firm values if its value to the Ringgit has been fixed? We believe that this has to do with the nature of the peg or more specifically with the exchange rate at which the Ringgit was pegged to the US\$. Over the 1980s until the currency crisis in mid-1997, the Ringgit was on a de facto peg to the US\$ at about 2.50 per US\$. Following the crisis and the sharp depreciation of the Ringgit, it was pegged to the US\$ at 3.80 per US\$ effective from 1 September 1998. At 3.80, the Ringgit has had a depreciation of $35 \%$ and was grossly undervalued by any measure. While it is one thing to peg and eliminate exchange 
rate volatility, it is another to peg at an 'undervalued' rate. When most listed firms are net importers, as our earlier results clearly show, an undervalued exchange rate destroys firm value. This value destruction will be ongoing and will continue as long as the peg is in place. Thus, firm values can change even though the exchange rate is unchanged. Unlike some policy changes that cause a one-off change and lead to a new equilibrium, here the crunch is continuous. Particularly, since the Malaysian economy has a myriad of price controls on a wide range of products making it difficult for higher import costs to be passed on. In contrast, net exporters like the plantation sector will experience consistent increase in firm value as long as the peg is in place, even if the US\$ price of commodity is unchanged. In short while, a peg can eliminate transaction exposure arising from that currency, it could under certain circumstances alter the competitiveness and thereby accentuate operating exposure.

Thus, in evaluating the efficacy of the fixed-peg, one can only conclude that the policy appears to have had no impact on reducing exchange rate exposure of firms but had adversely impacted the values of the vast majority of Malaysian listed firms that were net importers.

\section{Acknowledgements}

The authors gratefully acknowledge MOSTI and The Research Centre, IIUM for the financial support.

\section{References}

Adler, M. and Dumas, B. (1984) Exposure to currency risk: definition and measurement, Financial Management, 13, $41-50$.
Aquino, R. Q. (2006) Exchange rate risk and Philippine stock returns: before and after the Asian financial crisis, Applied Financial Economics, 15, 765-71.

Chue, T. K. and Cook, D. (2008) Engineering market exchange rate exposure, Journal of Banking and Finance, 32, 1349-62.

De Jong, A., Ligterink, J. and Macrae, V. (2006) A firm specific analysis of the exchange rate exposure of Dutch firms, Journal of International Financial Management and Accounting, 17, 1-29.

Dominguez, K. and Tesar, L. L. (2006) Exchange rate exposure, Journal of International Economics, 68, 188-218.

Ihrig, J. and Prior, D. (2005) The effect of exchange rate fluctuations on multinational's returns, Journal of Multinational Financial Management, 15, 273-86.

Kiymaz, H. (2003) Estimation of foreign exchange exposure: an emerging market application, Journal of Multinational Financial Management, 13, 71-84.

Lee, C. H., Doong, S. C. and Chou, P. I. (2011) Dynamic correlation between stock prices and exchange rates, Applied Financial Economics, 21, 789-800.

Muller, A. and Verschoor, W. F. C. (2007) Asian foreign exchange risk exposure, Journal of The Japanese and International Economies, 21, 16-37.

Parsley, D. C. and Popper, H. A. (2006) Exchange rate pegs and foreign exchange exposure in East and South East Asia, Journal of International Money and Finance, 25, 992-1009.

Phylaktis, K. and Ravazzolo, F. (2005) Stock prices and exchange rate dynamics, Journal of International Money and Finance, 24, 1031-53.

Rees, W. and Unni, S. (2005) Exchange rate exposure among European firms: evidence from France, Germany and the UK, Accounting and Finance, 45, 479-97.

Wong, K. N. and Tang, T. C. (2009) Exchange rate variability and export demand for Malaysia's semiconductors: an empirical study, Applied Economics, 43, 695-706. 


\section{Appendix}

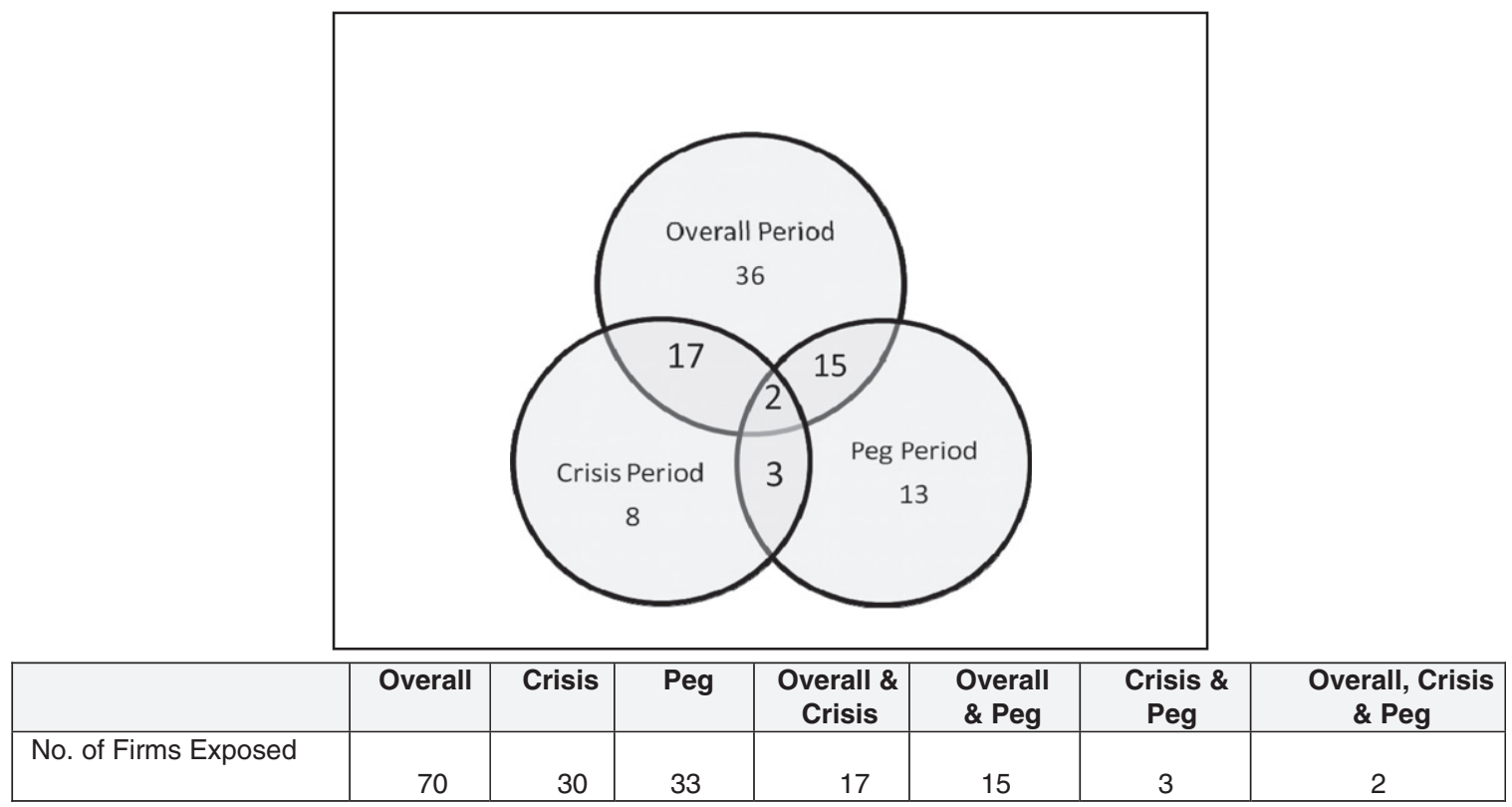

Fig. A1. US\$ exposure by periods

Table A1. Firm-specific and overall exposure (January 1990-December 2005)

\begin{tabular}{|c|c|c|c|c|c|c|}
\hline \multicolumn{7}{|c|}{ Panel A: Firms-specific exposure - using Equation 1} \\
\hline Number of observations & 158 & 158 & 158 & 158 & & \\
\hline Mean coefficient & -0.1573 & -0.0297 & 0.0126 & -0.1958 & & \\
\hline SD of coefficient & 1.1855 & 1.0176 & 0.3334 & 0.3674 & & \\
\hline Maximum coefficient & 1.7543 & 3.8973 & 1.1498 & 1.1052 & & \\
\hline Minimum coefficient & -3.9021 & -2.406 & -0.9588 & -1.1657 & & \\
\hline Firms with +ve coefficient & 35 & 13 & 12 & 6 & & \\
\hline Firms with - ve coefficient & 35 & 19 & 10 & 26 & & \\
\hline \multicolumn{7}{|c|}{ Panel B: Overall exposure (across full sample) - using Equation 2} \\
\hline usd | & $-0.2559162 *$ & 0.0503839 & -5.08 & 0.000 & -0.3546668 & -0.1571655 \\
\hline jpy | & -0.0188501 & 0.0264022 & -0.71 & 0.475 & -0.0705974 & 0.0328973 \\
\hline gbp | & $-0.2656522^{*}$ & 0.029002 & -9.16 & 0.000 & -0.322495 & -0.2088094 \\
\hline $\operatorname{sgd} \mid$ & 0.1333673 & 0.0692346 & 1.93 & 0.054 & -0.00233 & 0.2690645 \\
\hline _cons & $0.0047767 *$ & 0.0007343 & 6.51 & 0.000 & 0.0033376 & 0.0062159 \\
\hline
\end{tabular}

Note: * Denotes significance at $5 \%$ level. 


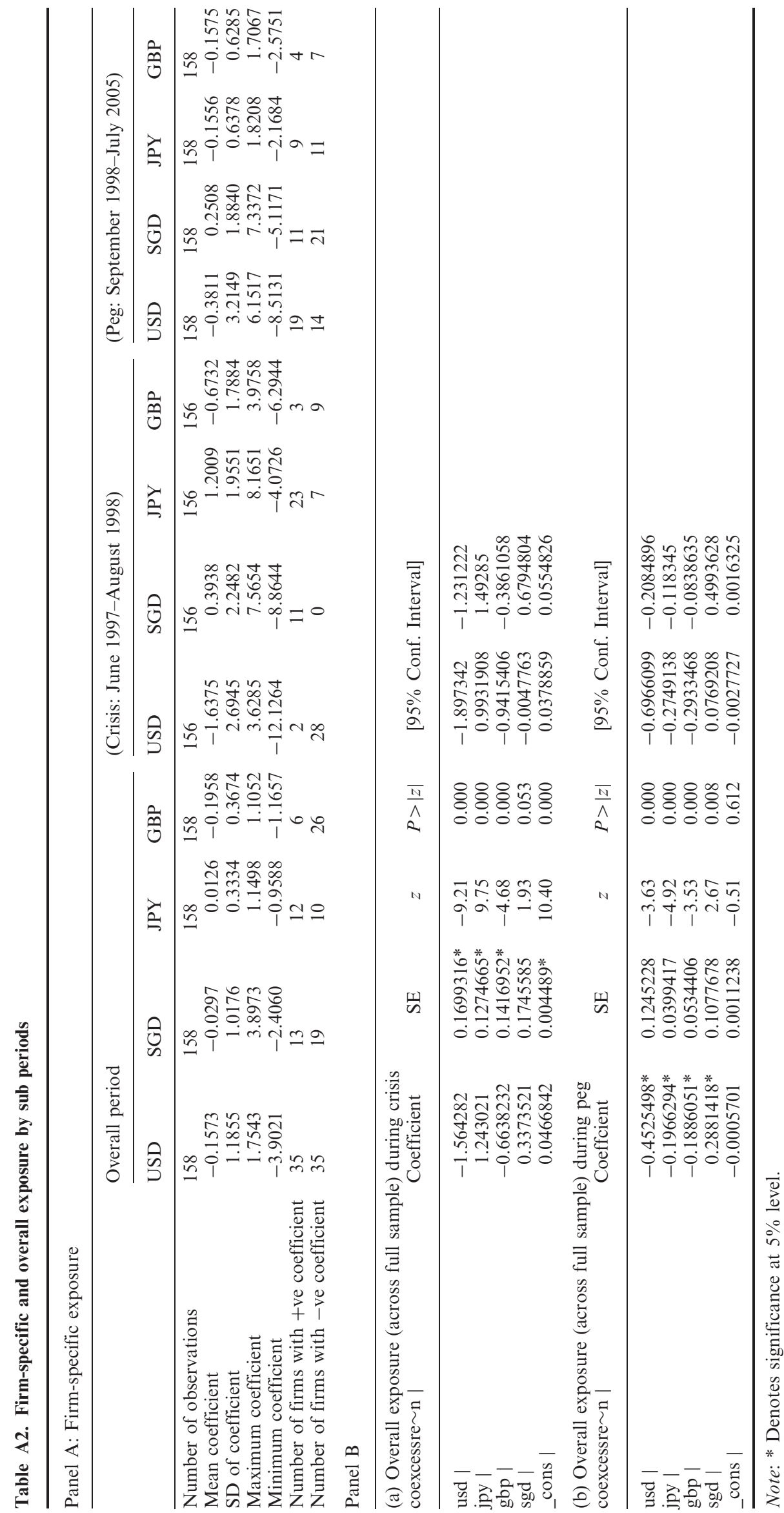


O. I. Bacha et al.

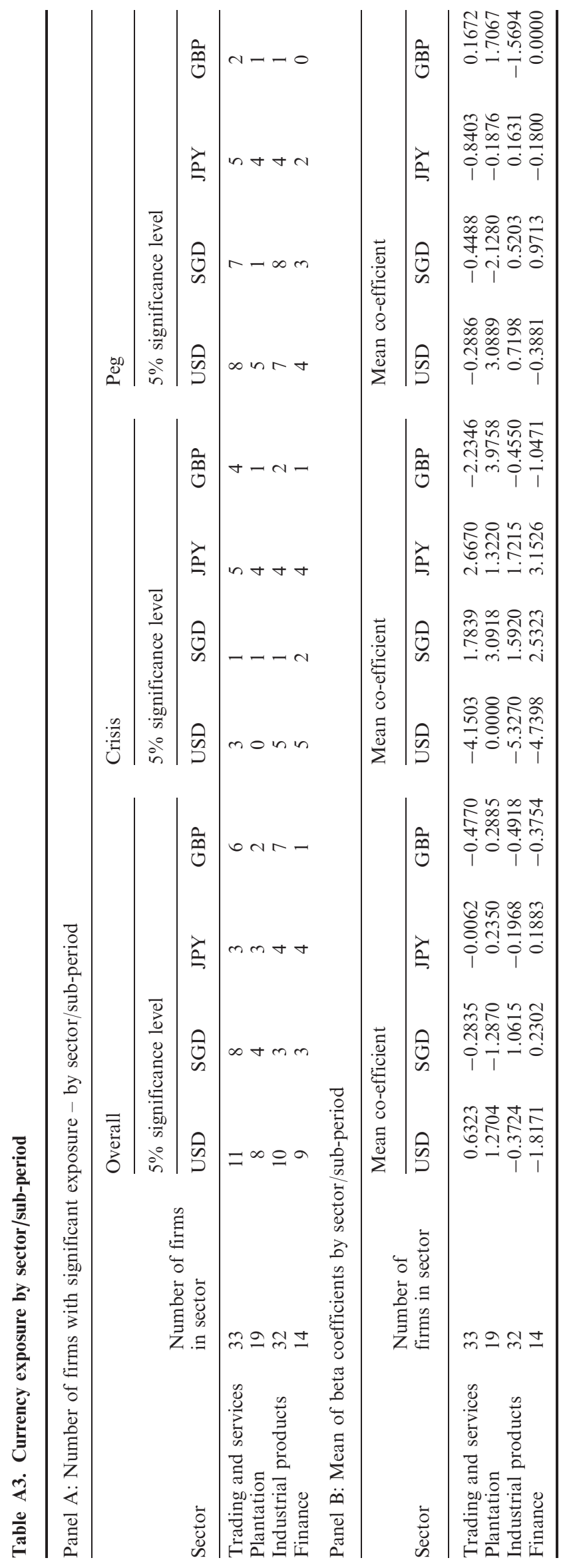

